\title{
Parasite Persistence in Treated Chagasic Patients Revealed by Xenodiagnosis and Polymerase Chain Reaction
}

\author{
Constança Britto/ ${ }^{+}$, Celeste Silveira**, Maria Angelica Cardoso, \\ Patricia Marques, Alejandro Luquetti***, Vanize Macêdo**, \\ Octavio Fernandes*
}

\begin{abstract}
Departamento de Bioquímica e Biologia Molecular *Departamento de Medicina Tropical, Instituto Oswaldo Cruz-Fiocruz, Av. Brasil 4365, 21045-900 Rio de Janeiro, RJ, Brasil **Departamento de Medicina Tropical, Universidade de Brasília, Brasília, DF, Brasil ***Instituto de Patologia Tropical e Saúde Pública, Universidade Federal de Goiás, Goiânia, GO, Brasil
\end{abstract}

Polymerase chain reaction (PCR) was compared with xenodiagnosis performed 20 years after trypanocidal chemotherapy to investigate parasite clearance. Eighty-five seropositive individuals for Chagas disease presenting a positive xenodiagnosis were treated with specific drugs; 37 in the acute phase and 48 in the chronic phase. Fifteen chronic assymptomatic patients received a placebo. Treatment in the acute phase led to PCR negative results in $73 \%$ of the cases, while xenodiagnosis was negative in $86 \%$. In the chronic phase, PCR was negative in $65 \%$ of the patients and $83 \%$ led to xenodiagnosis negative results. Regarding the untreated group (placebo), $73 \%$ gave negative results by xenodiagnosis, of which $36 \%$ were positive by PCR. Individuals that were considered seronegative $(n=10)$, presented unequivocally negative results in the PCR demonstrating the elimination of parasite DNA. Seventeen individuals had their antibodies titers decreased to such a level that the final results were considered as doubtful and 16 of them presented negative PCR. The molecular method represents a clear advantage over conventional techniques to demonstrate persistent infections in Chagas disease patients that underwent chemotherapy.

Key words: Trypanosoma cruzi - kinetoplast DNA - Chagas disease - PCR - treatment

The persistence of Trypanosoma cruzi in chronic lesions, revealed by molecular methods, supports the pathogenesis of Chagas disease mediated by presence of the parasite (Jones et al. 1993, Tarleton et al. 1997, Olivares-Villagómez et al. 1998, Añez et al. 1999). In fact, until recently, the current view was that auto-immune phenomenon was the major cause of clinical manifestations of the disease (Cunha-Neto et al. 1995, 1996). Probably the auto-immune component is a parasite-induced disorder (Tarleton \& Zhang 1999). Therefore, etiologic treatment should focus on clearance of parasites. Most human infections with T. cruzi are only detected in the chronic phase for which

Financial support by Faperj, Funasa and International Atomic Energy Agency. CB belongs to the FaperjFiocruz fellowship program.

${ }^{+}$Corresponding author. Fax: +55-21-590.3495. E-mail: cbritto@gene.dbbm.fiocruz.br

Received 19 September 2000

Accepted 18 April 2001 treatment is still controversial. Since conventional serological tests remain positive for years after successful therapy, a simple and safe procedure to assess cure is needed (Andrade et al. 1988, Gazzinelli et al. 1988). Negative xenodiagnosis and/or haemocultures have been used as evidence of effective treatment; however, these methods are time-consuming, laborious, uncomfortable for patients, and lack sensitivity (Brener et al. 2000). A complement mediated lysis (CoML) test has been proposed to monitor treatment (Galvão et al. 1993), but the requirement for living trypomastigotes limits its use.

Preliminary results revealed the potential use of polymerase chain reaction (PCR) assay to monitor cure in patients undergoing specific treatment (Britto et al. 1995). Therefore, we investigated the use of PCR by comparing the results with xenodiagnosis, for evaluating cure in a group of 85 initially xenopositive patients from two Brazilian endemic areas who received trypanocidal treatment in an average of 20 years ago.

A randomized trial of trypanocidal drug versus placebo treatment in Chagas disease patients 
was carried out in two Brazilian endemic areas in the 70s, at the Department of Tropical Medicine, University of Brasília, Federal District of Brazil (Silveira 2000). In that study 236 patients were enrolled, 111 in the acute phase and 125 in the chronic phase, presenting at least two out of three positive serologic tests for $T$. cruzi infection and positive results by xenodiagnosis. Their clinical state was determined through physical exam, conventional electrocardiography and thoracic radiography. All the individuals examined were diagnosed as unquestionably chagasic. The treated chronic patients, both who received trypanocidal drug or placebo were assymptomatic. These same areas were revisited 20 years afterwards and 99 patients could not be recruited. Eighteen had died, 50 had moved from the districts and no information could be gathered from 31 individuals. From the 137 remaining patients ( 40 treated in the acute phase, 58 treated in the chronic phase and 39 that received placebo), a subset of 100 individuals (37 treated in the acute phase, 48 treated in the chronic phase and 15 that received placebo) was selected for the present study. They were all inhabitants of two distinct geographic areas: 49 from São Felipe (State of Bahia) and 51 from Mambai (State of Goiás), where vector transmission has been interrupted for more than 15 years. Patients were treated with nifurtimox (7-8 mg/kg/day, $60-90$ days) or benznidazole (5-6 mg/kg/day, 30-60 days) (Silveira 2000).

The patients were followed-up by xenodiagnosis in an average of 20 years after treatment (range $=7-35$ years), as previously described (Marsden et al. 1979). Serology was performed by indirect immunofluorescence (IIF), indirect hemagglutination (IHA) tests and enzyme-linked immunosorbent assay (ELISA). Patients were considered positive when their sera reacted in two of these tests at a dilution of at least 1:80, 1:32 and 1.2 times higher than the cut off, respectively. Doubtful results corresponded to titers of 1:20 to $1: 40$ in the IIF, $1: 8$ to $1: 16$ in the IHA and results of 0.9 to 1.1 times higher than the cut off in the ELISA. PCR amplification of the variable region of the minicircle molecule was used to detect the presence of parasite mitochondrial DNA (kinetoplast DNA) in whole blood, as described elsewhere (Britto et al. 1993, Wincker et al. 1994). All the reactions were performed in duplicates and samples considered to be negative in the PCR assay with $T$. cruzi specific primers, were further tested with human $\beta$-globin gene primers, to discard eventual inhibitors to the PCR test (Wincker et al. 1994). Furthermore, to enhance the sensitivity of detection of the amplified products, hybridization experiments were performed in all negative samples and controls, using kinetoplast DNA from the $\mathrm{Y}$ strain MHOM/BR/00/Y (T. cruzi-II) as a radiolabeled molecular probe. No samples turned out to be positive after the hybridization step. Statistical analysis were performed with a statistical program of the EPI-INFO package version 6.0 using the Chisquare and Fisher's exact tests.

A total of 100 blood samples were analyzed: 85 from patients post-treatment for acute $(n=37)$, or chronic indeterminate $(\mathrm{n}=48)$ Chagas disease, and 15 from the chronic chagasic assymptomatic patients that received placebo. Table shows the results obtained with xenodiagnosis and the PCR test performed simultaneously with both groups of treated patients and the placebo group. Treatment in the acute phase resulted in conversion of xenodiagnosis to negative in $32 / 37$ (86\%) cases. The PCR was positive in 5/32 xeno-negative individuals plus all of the xeno-positive patients. Of the treated patients in the indeterminate chronic phase, 40/48 (83\%) had become xeno-negative, and PCR was positive in 9/40 of these and in all the xenopositive patients. Overall, PCR was positive in $27 \%$ (10/37 in the acute phase) and 35\% (17/48 in the chronic phase) of treated patients for acute or chronic phase, respectively.

In the untreated group (placebo), 11 out of 15 individuals were negative by the xenodiagnosis method (73\%), of which $36 \%$ were positive by PCR assay. All 4 xeno-positive patients had positive PCR results. The low sensitivity of PCR (53\%) and xenodiagnosis (27\%) in this group suggests a scarce parasitaemia. These data reinforce the higher sensitivity of the PCR when compared to xenodiagnosis, and suggest its adoption as gold standard for parasitologic cure.

Of the 27 patients that were treated in the acute phase and presented negative results by PCR, 5 showed a doubtful serology 20 years afterwards and 7 had negative serological results. Considering the patients treated in the chronic phase, nega-

\section{TABLE}

Polymerase chain reaction (PCR) results in relation to xenodiagnosis in samples from treated chagasic patients and placebo group (untreated chronic assymptomatic controls). The column Xeno - and $\mathrm{PCR}+$ (bold) represent the advantage of the molecular technique over the traditional parasitological diagnosis

\begin{tabular}{lcccccc}
\hline & \multirow{2}{*}{$(\mathrm{N})$} & \multicolumn{2}{c}{ Xeno +} & & \multicolumn{2}{c}{ Xeno - } \\
\cline { 3 - 4 } & & PCR - & PCR & & PCR - & PCR+ \\
\hline Acute phase & 37 & 0 & 5 & & 27 & $\mathbf{5}$ \\
Chronic phase & 48 & 0 & 8 & & 31 & $\mathbf{9}$ \\
Placebo group & 15 & 0 & 4 & & 7 & $\mathbf{4}$ \\
\hline
\end{tabular}


tive serological results were evidenced in 3 and 12 showed doubtful results. No patients with an actual negative serology presented a PCR positive result $(n=10)$. However, one patient that was treated in the chronic phase presenting a doubtful serological result showed T. cruzi DNA amplification. Indeed, the negative serology was a good marker for cure in this study since all of them were PCR negative.

At present, nifurtimox or benznidazole are indicated for the acute $T$. cruzi infections, for infected children and also for chronic chagasic patients that are either in the indeterminate form or in the early symptomatic stage (Ministério da Saúde 1997). However, there are many difficulties involved in the evaluation of the efficacy of parasiticidal treatment mainly during the chronic phase of Chagas disease (Brener 1984).

PCR presented a higher positivity than the xenodiagnosis method for detecting parasites in all studied groups, although it was statistically significant only in the group comprised of chronic patients that received trypanocidal drug (17 PCR positive results versus 8 xenopositive individuals in 48 patients; $\chi^{2}=4.34, p=0.03$ ). For instance, $13 \%$ of treated patients in the acute Chagas disease gave a positive PCR result while the xenodiagnosis had become negative. In the chronic phase, $18 \%$ of the cases were under-diagnosed by the xenodiagnosis procedure. These patients that are xeno-negative and PCR-positive should be followed-up, in order to demonstrate the role of the presence of circulating DNA, shown by PCR, in the evolution of symptoms. Regarding the untreated group, PCR presented a negative result in $47 \%$ of the cases. This rate may reflect the intermittent parasitaemia that is usually found in chronic chagasic patients, even in those who were treated and did not present parasitological cure.

The interpretation of PCR may be raise controversial. A positive result may reflect the detection of intact parasites or circulating DNA. However, Tarleton and Zhang (1999) described that after the intra-muscular injection of large quantities of kDNA, PCR was positive only for two days after the injection and not thereafter. The authors discuss that this study strongly supports the hypothesis that parasite DNA detected by PCR is derived from intact, extracellular or recently lysed parasites.

A negative post-treatment PCR result may be indicative of the absence of parasite DNA at that moment. In our scenario, as only one point in time was analyzed, a negative result could not be assumed as definitive cure. In the present study, all the individuals that became negative by serological tests performed 20 years after chemotherapy, also demonstrated the elimination of circulating DNA by the PCR method (data not shown). The agreement of negative results between serology and PCR, is probably indicative of cure. Although these data indicate that PCR is more reliable and sensitive than xenodiagnosis to assess cure after specific treatment, the use of a single assay, as performed in this setting, is not sufficient to reach a final conclusion on parasite DNA clearance in post-treatment patients. Follow-up studies with a continuos screening of individuals, using the molecular technique plus serology, should be carried out.

\section{REFERENCES}

Andrade SG, Freitas LAR, Peyrol S, Pimentel AR, Sadigursky M 1988. Trypanosoma cruzi antigens detected by immunoelectron microscopy in the spleen of mice serologically positive but parasitologically cured by chemotherapy. Rev Soc Bras Med Trop 21: 41-42.

Añez N, Carrasco H, Parada H, Crisante G, Rojas A, Fuenmayor C, Gonzalez N, Percoco G, Borges R, Guevara P, Ramirez JL 1999. Myocardial parasite persistence in chronic chagasic patients. Am J Trop Med Hyg 60: 726-732.

Brener Z 1984. Recent advances in the chemotherapy of Chagas' disease. Mem Inst Oswaldo Cruz 79: 149155.

Brener Z, Andrade Z, Barral-Neto M 2000. Tratamento etiológico da doença de Chagas pelo benzonidazol. In Z Brener, Z Andrade, M Barral-Neto (eds), Trypanosoma cruzi e Doença de Chagas, 2nd ed., Guanabara Koogan, Rio de Janeiro, p. 389-405.

Britto C, Cardoso MAB, Wincker P, Morel CM 1993. A simple protocol for the physical cleavage of Trypanosoma cruzi kinetoplast DNA present in blood samples and its use in polymerase chain reaction (PCR)-based diagnosis of chronic Chagas disease. Mem Inst Oswaldo Cruz 88: 171-172.

Britto C, Cardoso MA, Vanni CMM, Haslocher-Moreno A, Xavier SS, Oelemann W, Santoro A, Pirmez C, Morel CM, Wincker P 1995. Polymerase chain reaction detection of Trypanosoma cruzi in human blood samples as a tool for diagnosis and treatment evaluation. Parasitology 110: 241-247.

Cunha-Neto E, Coelho V, Guilherme L, Fiorelli A, Stolf N, Kalil J 1996. Autoimmunity in Chagas disease. Identification of cardiac myosin-B13 Trypanosoma cruzi protein crossreactive T cell clones in heart lesions of a chronic Chagas' cardiomyopathy patient. J Clin Invest 98: 1709-1712.

Cunha-Neto E, Duranti M, Gruber A, Zingales B, De Messias I, Stolf N, Bellotti G, Patarroyo ME, Pilleggi F, Kalil J 1995. Autoimmunity in Chagas disease cardiopathy: biological relevance of a cardiac myosin-specific epitope crossreactive to an immunodominant Trypanosoma cruzi antigen. Proc Natl Acad Sci USA 92: 3541-3545.

Galvão LMC, Nunes RMB, Cançado JR, Krettli AU 1993. Lytic antibody as a means of assessing cure after treatment of Chagas disease: a 10 years fol- 
low-up study. Trans $R$ Soc Trop Med Hyg 87: 220223.

Gazzinelli RT, Galvão LMC, Cardoso JE, Cançado JR, Krettli AU, Brener Z, Gazzinelli G 1988. Anti-Trypanosoma cruzi and anti-laminin antibodies in chagasic patients after specific treatment. J Clin Microb 26: 1795-1800.

Jones EM, Colley DG, Tostes S, Lopes ER, VnencakJones CL, McCurley TL 1993. Amplification of a Trypanosoma cruzi DNA sequence from inflammatory lesions in human chagasic cardiomyopathy. Am J Trop Med Hyg 48: 348-357.

Marsden PD, Barreto AC, Cuba CC, Gama MB, Ackers J 1979. Improvements in routine xenodiagnosis with first instar Dipetalogaster maximus (Uhler, 1894) (Triatominae). Am J Trop Med Hyg 28: 649-652.

Ministério da Saúde 1997. Tratamento Etiológico da Doença de Chagas, 2nd ed., Fundação Nacional de Saúde, Brasília, 32 pp.

Olivares-Villagomez D, Lane JE, Vnencak-Jones CL, McCurley TL, Carter CE 1998. Polymerase chain reaction amplification of three different Trypanosoma cruzi DNA sequences from human chagasic cardiac tissue. Am J Trop Med Hyg 59: 563-570.

Silveira CAN 2000. Avaliação a Longo Prazo do Tratamento Específico da Doença de Chagas, $\mathrm{PhD}$ Thesis, Faculdade de Medicina, Universidade de Brasília, Distrito Federal, 123 pp.

Tarleton RL, Zhang L 1999. Chagas disease etiology: autoimmunity or parasite persistence? Parasitol Today 15: 94-99.

Tarleton RL, Zhang L, Downs MO 1997. Autoimmune rejection of neonatal heart transplants in experimental Chagas' disease is a parasite-specific response to infected host tissue. Proc Natl Acad Sci USA 94: 3932-3937.

Wincker P, Britto C, Pereira JB, Cardoso MA, Oelemann W, Morel CM 1994. Use of a simplified polymerase chain reaction procedure to detect Trypanosoma cruzi in blood samples from chronic chagasic patients in a rural endemic area. Am J Trop Med Hyg 51: 771-777. 